\title{
Establishment and analysis of temperature field of riserless mud recovery system
}

\author{
Jie Zhang*, Xin Li, Xu Tang, and Wen Luo \\ State Key Laboratory of Oil and Gas Reservoir Geology and Exploitation, Southwest Petroleum University (SWPU), Chengdu, \\ Sichuan, China
}

Received: 15 September 2018 / Accepted: 11 December 2018

\begin{abstract}
Due to the drill pipe in the Riserless Mud Recovery (RMR) system is exposed to seawater, so the characteristics of the temperature changing are very different from the conventional offshore drilling. Considering temperature is an important factor affecting the annulus pressure, it is necessary to study the variation law of the temperature field of the RMR. In this paper, according to the physical process of the heat transfer in RMR, the mathematical model of the temperature field is established. The Computational Fluid Dynamics (CFD) software is used to simulate the temperature distribution in the drill pipe and the annulus, so that the law of the temperature changing can be observed more intuitively. In order to be more aware of the influencing factors of the temperature field changing, this paper analyzes the influence mechanism of the different discharge capacity and the different injection temperature on temperature changing. Moreover, this paper also analyzes the influence of the annulus temperature on the annulus pressure, which provides a theoretical basis for the well control of RMR.
\end{abstract}

\section{Introduction}

Riserless Mud Recovery (RMR) system is an advanced offshore drilling technology developed by Norwegian AGR Company (Stave et al., 2008). Compared with the conventional offshore drilling, RMR adopts the dual-gradient control principle to control the annulus pressure more precisely, so as to effectively solve problems such as narrow mud density window, shallow gas and shallow flow that the offshore drilling engineering has always been facing (Michael and Michael, 2001; Myers, 2008; Smith et al., 2010; Stave et al., 2008). Because RMR abandons the riser used in the traditional offshore drilling and uses a seabed pump as a device for lifting drilling fluid, it reduces the cost of drilling and the demand for drilling platform (Claudey et al., 2016; Gao et al., 2009; Hannegan and Stave, 2006; Stave et al., 2014). From the above two points, RMR is suitable for drilling in deep water and ultra-deep water, which is in line with the development trend of the current offshore drilling engineering.

As shown in Figure 1, the RMR consists of three modules: the suction module, the subsea pump and the return line (Cohen et al., 2010). The suction module is used to collect the mud returned from the annulus and seal the wellhead (Scanlon and Medeiros, 2012). The outlet of the suction module is connected to the inlet of the seabed pump

\footnotetext{
* Corresponding author: swpivip@163.com
}

through a hose. The subsea pump belongs to the disc pump and has been developed to the third generation (Alford et al., 2005; Beek et al., 2016). Its main function is to provide power for the lifting of the mud and by adjusting its pump speed, the pressure acting on the wellhead is equal to the static pressure of seawater at this depth, thus achieving dual-gradient. The return line is the only channel for mud to return to the platform from the seabed (Wang, 2013). The pipe size and arrangement mode of the return line will greatly affect the lifting efficiency of mud (Stave et al., 2005; Thorogood et al., 2007).

Because the drill pipe in RMR is directly exposed to seawater, the characteristics of the temperature changing of the wellbore are greatly different from the conventional offshore drilling due to the variation of the seawater temperature gradient. Temperature is an important factor affecting the annulus pressure. In order to make RMR successfully applied in the deep water and the ultra-deep water, and achieve higher precision of the annulus pressure control, it is necessary to study the temperature variation characteristics in RMR in combination with the characteristics of the temperature changing of the marine environment and explore the influence mechanism of the temperature changing.

Since RMR is an emerging drilling technology, its related theory is not very mature so far, which limits the development of RMR to deep water and ultra deep water. Only Norwegian AGR Company has been successful in 


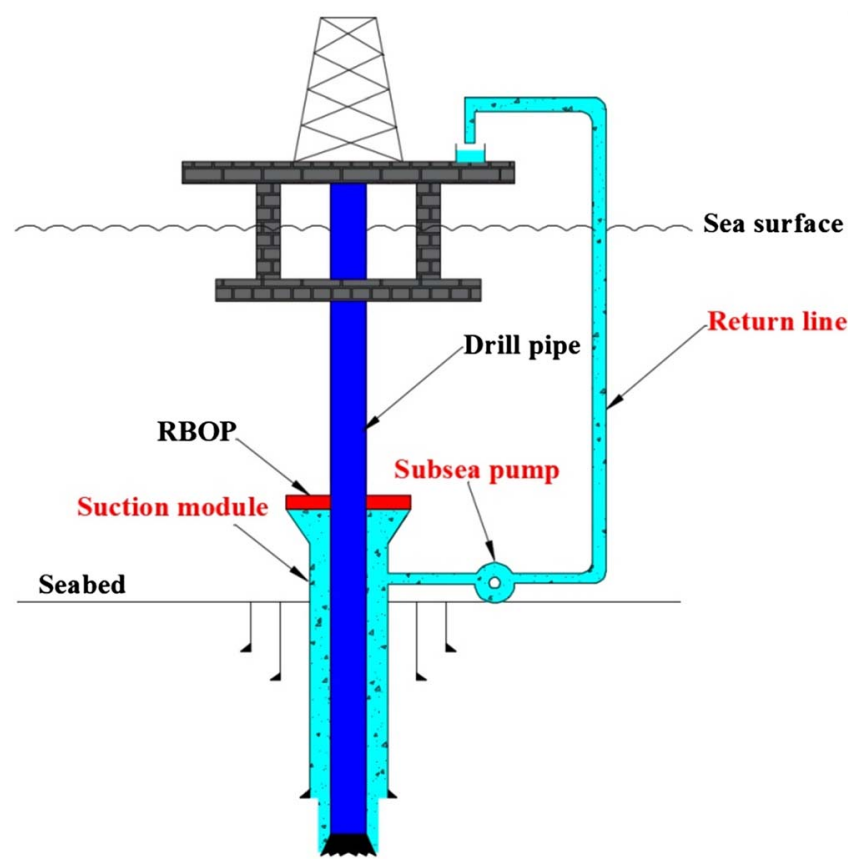

Fig. 1. Composition of the RMR system.

implementing it commercially, but only in the shallow water (Eikemo, 2015; Ziegler et al., 2013). Currently, RMR is not widely used in deep water and ultra-deep water worldwide (Chen et al., 2007; Peyton et al., 2013). In order to strengthen the development of oil and gas resources in deep water and ultra deep water, it is necessary to carry out a deeper theoretical research based on the technical characteristics and advantages of RMR, which is crucial for the development of the offshore oil and gas engineering.

\section{Mathematical model}

\subsection{Basic assumed conditions}

Since the drill pipe and the annulus are symmetric models, they can be simplified to a two-dimensional planar model for calculation. A drilling fluid control body of length $\mathrm{d} x$ is taken in the drill pipe and the annulus respectively, and the flow direction of drilling fluid is set to positive direction, and the following assumed conditions are made:

1. The temperature in any section of drill pipe and annulus perpendicular to the flow direction is uniform.

2. Ignore the heat conduction along the flow direction.

3. All physical properties are constants.

4. No insulation layer is set on the outer wall of drill pipe.

\subsection{Mathematical model in drill pipe}

The physical model of heat transfer process of drill pipe exposed to seawater is shown in Figure 2. body:

The heat injected from the upper surface of the control

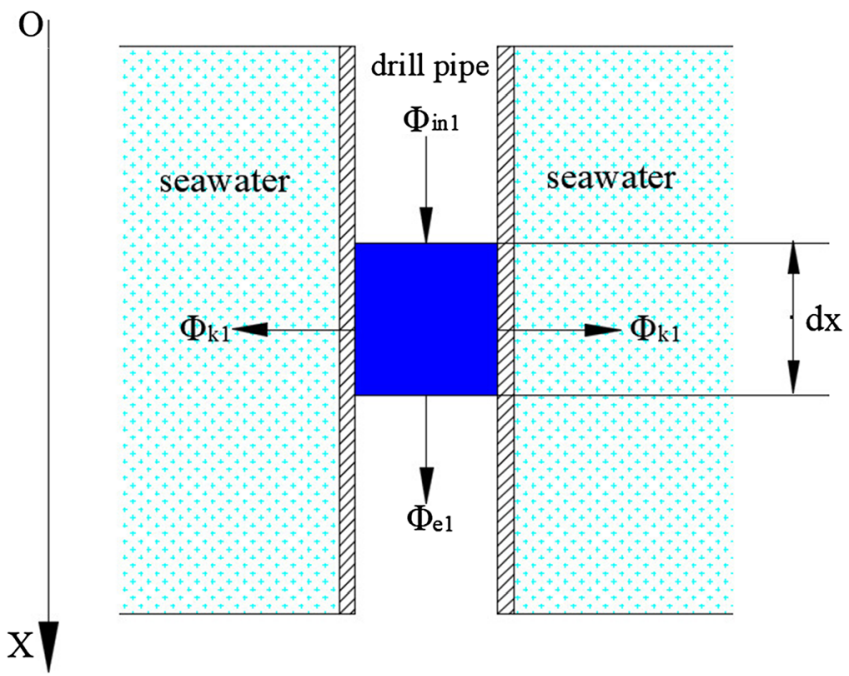

Fig. 2. Heat transfer model of drill pipe.

$$
\Phi_{\mathrm{in} 1}=q_{\mathrm{m} 1} c_{\mathrm{p}} t_{x}
$$

The heat that flows from the lower surface of the control body:

$$
\Phi_{\mathrm{e} 1}=q_{\mathrm{m} 1} c_{\mathrm{p}} t_{x+\mathrm{d} x} .
$$

Heat transferred from the drilling fluid in the drill pipe to seawater:

$$
\Phi_{\mathrm{k} 1}=k_{1} \pi d_{1}\left(t_{x}-t_{\mathrm{sea}}\right) \mathrm{d} x .
$$

Because the law of seawater temperature decline in different sea areas is different, this paper uses the law of seawater temperature change in the South China Sea as the calculation method of seawater temperature (Vaid and Polito, 2016; Wang et al., 2010):

$$
t_{\text {sea }}=\left[\left(t_{0}-22.315\right)(200-x)+13.7 x\right] / 200 .
$$

According to the law of conservation of energy $\left(\Phi_{\text {in }}=\Phi_{\text {out }}\right)$, the temperature profile of the drilling fluid in the drill pipe can be obtained from the above four equations:

$\frac{\mathrm{d} t}{\mathrm{~d} x}+\frac{k_{1} \pi d_{1}}{q_{\mathrm{m} 1} c_{\mathrm{p}}} t=\frac{k_{1} \pi d_{1}}{200 q_{\mathrm{m} 1} c_{\mathrm{p}}}\left[\left(t_{0}-22.315\right)(200-x)+13.7 x\right]$.

Combined with boundary condition $t_{x=0}=t_{\text {i }}$, the calculation equation of the temperature of the drilling fluid in drill pipe can be obtained:

$$
t=A_{1} x+B_{1} e^{C_{1} x}+D_{1},
$$

$$
A_{1}=\frac{\left(t_{0}-36.015\right)}{200},
$$

$$
B_{1}=\left(t_{\mathrm{i}}-t_{0}+22.315\right)+\frac{\left(36.015-t_{0}\right) q_{\mathrm{m} 1} c_{\mathrm{p}}}{200 k_{1} \pi d_{1}}
$$




$$
\begin{gathered}
C_{1}=-\frac{k_{1} \pi d_{1}}{q_{\mathrm{m} 1} c_{\mathrm{p}}}, \\
D_{1}=\left(t_{0}-22.315\right)+\frac{\left(t_{0}-36.015\right) q_{\mathrm{m} 1} c_{\mathrm{p}}}{200 k_{1} \pi d_{1}},
\end{gathered}
$$

where $t_{0}$ is the temperature of sea surface, ${ }^{\circ} \mathrm{C} ; t_{\mathrm{i}}$ is the injection temperature of drilling fluid, ${ }^{\circ} \mathrm{C} ; q_{\mathrm{m} 1}$ is the mass flow of drilling fluid through control body, $\mathrm{kg} / \mathrm{s} ; c_{\mathrm{p}}$ is the specific heat capacity of drilling fluid, $\mathrm{J} /\left(\mathrm{kg}{ }^{\circ} \mathrm{C}\right) ; k_{1}$ is the heat transfer coefficient between drilling fluid in drill pipe and seawater, $\mathrm{W} /\left(\mathrm{m}^{2}{ }^{\circ} \mathrm{C}\right) ; d_{1}$ is the inner diameter of drill pipe, $\mathrm{m}$; $t_{x}$ is the temperature of drilling fluid at $x,{ }^{\circ} \mathrm{C}$; $t_{x+\mathrm{d} x}$ is the temperature of drilling fluid at $x+\mathrm{d} x,{ }^{\circ} \mathrm{C}$.

\subsection{Mathematical model in annulus}

The physical model of heat transfer process of annulus is shown in Figure 3.

The heat injected from the lower surface of the control body:

$$
\Phi_{\mathrm{in} 2}=q_{\mathrm{m} 2} c_{\mathrm{p}} t_{x}
$$

The heat transfer from the formation to the drilling fluid in the annulus:

$$
\Phi_{\text {in } 3}=k_{2} \pi\left(d_{3}-d_{2}\right)\left(t_{\text {for }}-t_{x}\right) \mathrm{d} x .
$$

The temperature of the formation at depth $x$ :

$$
t_{\text {for }}=t_{\mathrm{s}}+m(L-x) \text {. }
$$

The heat that flows from the upper surface of the control body:

$$
\Phi_{\mathrm{e} 2}=q_{\mathrm{m} 2} c_{\mathrm{p}} t_{x+\mathrm{d} x} .
$$

The heat transfer from the drilling fluid in annulus to the drilling fluid in drill pipe:

$$
\Phi_{\mathrm{k} 2}=k_{3} \pi\left(d_{3}-d_{2}\right)\left(t_{\mathrm{x}}-t_{\mathrm{e}}\right) \mathrm{d} x .
$$

According to the law of conservation of energy, and combined with the boundary condition $t_{x=0}=t_{\mathrm{u}}$, the calculation equation of the temperature of drilling fluid in annulus can be obtained:

$$
\begin{gathered}
t=A_{2} x+B_{2} \mathrm{e}^{\mathrm{C}_{2} x}+D_{2}, \\
A_{2}=-\frac{m k_{2}}{k_{2}+k_{3}}, \\
B_{2}=-\frac{k_{2} t_{\mathrm{u}}+k_{3} t_{\mathrm{e}}}{k_{2}+k_{3}}-\frac{m k_{2} q_{\mathrm{m} 2} c_{\mathrm{p}}}{\pi\left(d_{3}-d_{2}\right)\left(k_{2}+k_{3}\right)^{2}}, \\
C_{2}=-\frac{\left(k_{2}+k_{3}\right) \pi}{q_{\mathrm{m} 2} c_{\mathrm{p}}}\left(d_{3}-d_{2}\right), \\
D_{2}=B_{2},
\end{gathered}
$$

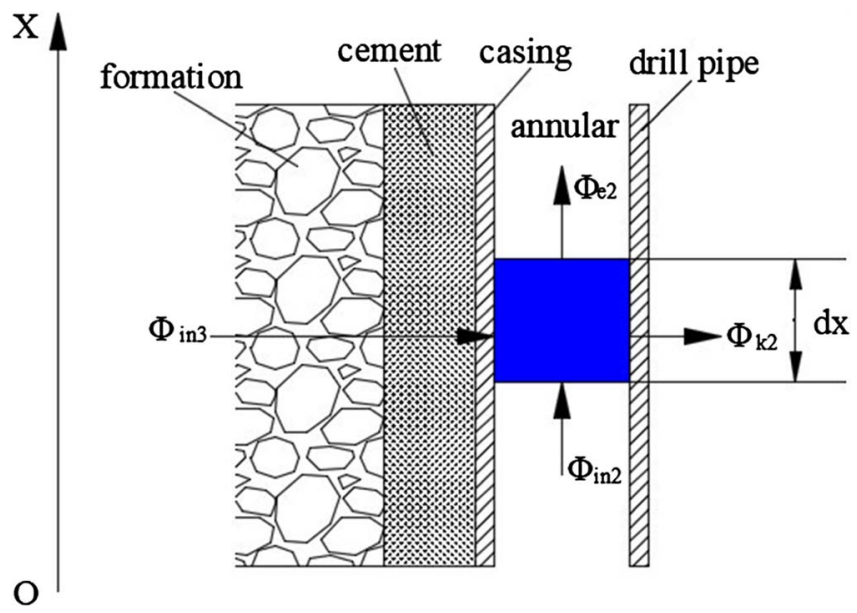

Fig. 3. Heat transfer model of annulus.

where $k_{2}$ is the heat transfer coefficient between the formation and the drilling fluid in annulus, $\mathrm{W} /\left(\mathrm{m}^{2}{ }^{\circ} \mathrm{C}\right)$; $k_{3}$ is the heat transfer coefficient between the drilling fluid in annulus and the drilling fluid in drill pipe, $\mathrm{W} /\left(\mathrm{m}^{2}{ }^{\circ} \mathrm{C}\right)$; $t_{\mathrm{u}}$ is the temperature of the drilling fluid at the bottom of well, ${ }^{\circ} \mathrm{C} ; t_{\mathrm{e}}$ is the temperature of the drilling fluid in drill pipe, ${ }^{\circ} \mathrm{C}$; $t_{\mathrm{s}}$ is the surface temperature of formation, ${ }^{\circ} \mathrm{C} ; m$ is geothermal gradient, ${ }^{\circ} \mathrm{C} / 100 \mathrm{~m} ; q_{\mathrm{m} 2}$ is the mass flow of drilling fluid through control body, $\mathrm{kg} / \mathrm{s} ; d_{3}$ is the diameter of annulus, $\mathrm{m} ; d_{2}$ is the outer diameter of drill pipe, $\mathrm{m}$.

\section{CFD analysis}

In order to observe the changing of temperature field intuitively, and to provide a certain basis for the verification of the mathematical model, this paper uses Computational Fluid Dynamics (CFD) software to carry out numerical simulation of some well sections. The model is scaled to a certain scale in this paper, but the heat exchange time is still the same as the actual situation. The basic data used in simulation is from a real well in the South China Sea (Gao et al., 2013).

\subsection{CFD analysis for drill pipe}

The temperature changing of the drilling fluid in drill pipe at water depth 0-1000 m was simulated. The basic parameters are shown in Table 1.

The finite element model of drill pipe is established, as shown in Figure 4. Considering that the flow of the drilling fluid in drill pipe is turbulent for most of the time, it is necessary to add boundary layer near the wall when establishing the finite element model.

In order to make the observation more clearly, this paper simulates the temperature changing of the drilling fluid in drill pipe at water depth $0-500 \mathrm{~m}$ and $500-1000 \mathrm{~m}$ respectively. The results of the CFD analysis are shown in Figures 5 and 6 . 
Table 1. Input parameters for CFD.

\begin{tabular}{lclc}
\hline Parameter & Value & Parameter & Value \\
\hline Density of drilling fluid, $\mathrm{kg} / \mathrm{m}^{3}$ & 1250 & Discharge capacity, $\mathrm{L} / \mathrm{s}$ & 35 \\
Viscosity of drilling fluid, $\mathrm{Pa} / \mathrm{s}$ & 0.045 & Heat transfer coefficient $k_{1}, \mathrm{~W} /\left(\mathrm{m}^{2}{ }^{\circ} \mathrm{C}\right)$ & 179.9 \\
Injection temperature of drilling fluid, ${ }^{\circ} \mathrm{C}$ & 20 & Wall thickness of drill pipe, $\mathrm{m}$ & 0.059 \\
\hline
\end{tabular}

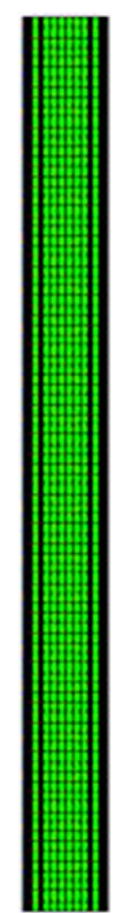

Fig. 4. The finite element model of drill pipe.

As can be seen from Figures 5 and 6, the injection temperature of the drilling fluid at $0 \mathrm{~m}$ is $20^{\circ} \mathrm{C}$, the temperature at $500 \mathrm{~m}$ is about $14{ }^{\circ} \mathrm{C}$, and the temperature at $1000 \mathrm{~m}$ is about $10^{\circ} \mathrm{C}$. At the entire stage of $0-1000 \mathrm{~m}$, the temperature of drilling fluid is reduced by about $50 \%$ due to the influence of the temperature gradient of seawater. From the results of CFD analysis, the temperature distribution of the drilling fluid in drill pipe is largely affected by seawater temperature when the insulation layer is not installed.

\subsection{CFD analysis for annulus}

The temperature changing of the drilling fluid in annulus at formation depth 5000-6000 $\mathrm{m}$ and $3500-4000 \mathrm{~m}$ was simulated. The basic parameters are shown in Table 2 .

The finite element model of annulus is established, as shown in Figure 7. The flow of the drilling fluid in annulus is also in a turbulent state for most of the time. Therefore, it is necessary to set a boundary layer near the wall of the finite element model of annulus. And because annulus is a symmetric figure, so it can be simulated in half.

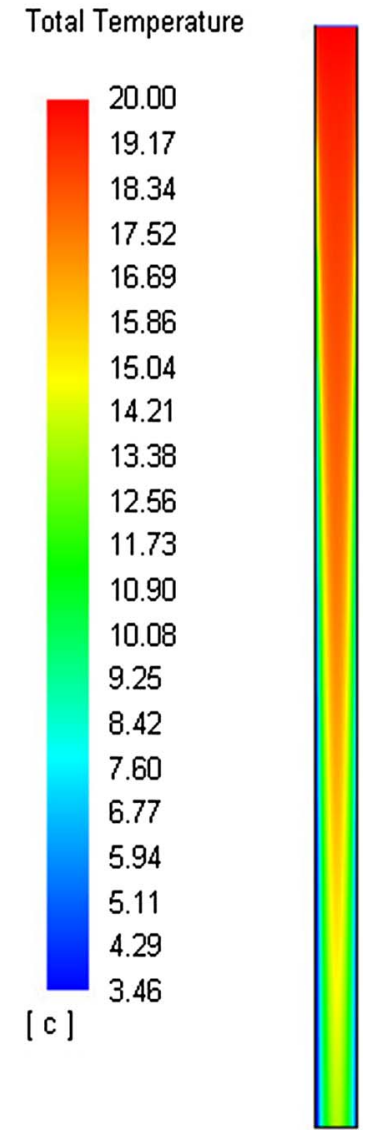

Fig. 5. CFD analysis results of $0-500 \mathrm{~m}$.

The results of the CFD analysis are shown in Figures 8 and 9 .

As can be seen from Figures 8 and 9, the temperature of the drilling fluid at formation depth $6000 \mathrm{~m}$ is about $63^{\circ} \mathrm{C}$, and it is about $78{ }^{\circ} \mathrm{C}$ at $5500 \mathrm{~m}$, which is about $15{ }^{\circ} \mathrm{C}$ higher. The temperature of the drilling fluid at formation depth $4000 \mathrm{~m}$ is about $92^{\circ} \mathrm{C}$, and it is about $83^{\circ} \mathrm{C}$ at $3500 \mathrm{~m}$, which is about $9{ }^{\circ} \mathrm{C}$ lower. Therefore, when the drilling fluid returns in annulus, the temperature changing trend of drilling fluid is first increased and then decreased.

\section{Case study}

In this section, based on the basic data of a well in the South China Sea (Gao et al., 2013), the mathematical 


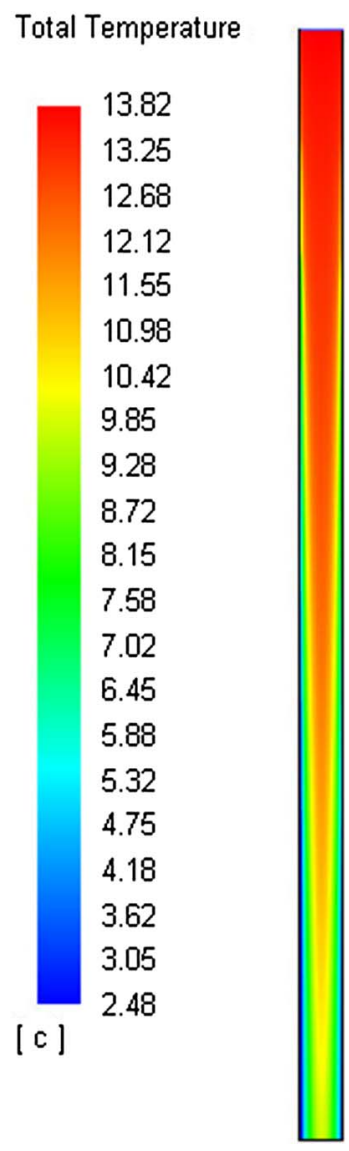

Fig. 6. CFD analysis results of 500-1000 m.

model is used for calculation, and the results are compared with the results of CFD analysis, so as to verify the feasibility of the mathematical model. The temperature variation characteristics of the drilling fluid in drill pipe and annulus under the influence of the different discharge capacity and different injection temperature are analyzed. The effect of temperature on annulus pressure are also analyzed in this section. The basic data of the well is shown in Table 3.

\subsection{Influence of different discharge capacity}

When the injection temperature of drilling fluid is $20^{\circ} \mathrm{C}$, the discharge capacity is set to $35 \mathrm{~L} / \mathrm{s}, 45 \mathrm{~L} / \mathrm{s}, 55 \mathrm{~L} / \mathrm{s}$ and $65 \mathrm{~L} / \mathrm{s}$. The results of calculation are shown in Figures 10 and 11.

It can be seen from Figure 10 that when the injection temperature of drilling fluid is $20^{\circ} \mathrm{C}$ and the discharge capacity is $35 \mathrm{~L} / \mathrm{s}$, the temperature of the drilling fluid in drill pipe at seawater depth $500 \mathrm{~m}$ is about $13{ }^{\circ} \mathrm{C}$, and about $11^{\circ} \mathrm{C}$ at $1000 \mathrm{~m}$. As can be seen from Figure 11, the temperature of the drilling fluid at formation depth $6000 \mathrm{~m}$ is about $62{ }^{\circ} \mathrm{C}$, about $78{ }^{\circ} \mathrm{C}$ at $5500 \mathrm{~m}$, about $91{ }^{\circ} \mathrm{C}$ at $4000 \mathrm{~m}$, and about $85^{\circ} \mathrm{C}$ at $3500 \mathrm{~m}$. This result is basically consistent with the result of CFD analysis.
Therefore, the mathematical model of the temperature field established in this paper has certain accuracy.

As can be seen from Figures 10 and 11, as the discharge capacity increases, the temperature of the drilling fluid in drill pipe and annulus will increase. This is because when the displacement is increased, the heat exchange time between the drilling fluid and the seawater is shortened, so that the temperature decrease of drilling fluid is reduced, and the temperature at the bottom of well is higher. Therefore, in order to maintain the temperature of the drilling fluid, the discharge capacity can be increased to some extent in combination with the actual situation.

\subsection{Influence of different injection temperature}

When the discharge capacity is $35 \mathrm{~L} / \mathrm{s}$, the injection temperature of drilling fluid is set to $20^{\circ} \mathrm{C}, 25^{\circ} \mathrm{C}, 30^{\circ} \mathrm{C}$ and $35^{\circ} \mathrm{C}$. The results of calculation are shown in Figures 12 and 13 .

As can be seen from Figures 12 and 13, the higher the injection temperature of drilling fluid is, the higher the temperature of drilling fluid at the same water depth and the same formation depth is. This is because when the drilling fluid has the same properties and the discharge capacity is the same, when the injection temperature of drilling fluid increases, the heat $\Phi_{\mathrm{in} 1}$ and $\Phi_{\mathrm{in} 2}$ entering the control body increase. Combined with equations (1) and (11), it can be seen that as $\Phi_{\mathrm{in} 1}$ and $\Phi_{\mathrm{in} 2}$ increase, the temperature of the drilling fluid at the same water depth and formation depth will increase.

\subsection{Analysis of variation characteristics}

It can be seen from Figures 10 to 12 that when the water depth is less than $1000 \mathrm{~m}$, as the water depth increases, the temperature of the drilling fluid in drill pipe becomes lower and lower, and the extent of decrease is larger. This is because the temperature of seawater at this stage is getting lower and lower as the water depth increases, and the amount of heat exchange between the drilling fluid and the seawater is increasing. However, when the water depth is greater than $1000 \mathrm{~m}$, the temperature of drilling fluid remains substantially constant. This is because the temperature of seawater at this stage reaches the constant temperature layer (Vaid and Polito, 2016), and the temperature of seawater no longer decreases with the increase of water depth. At this time, the heat exchange between the drilling fluid and the seawater is extremely small, so the temperature of drilling fluid is basically stable.

It can be seen from Figures 11 to 13 that when the drilling fluid returns in annulus, the temperature of drilling fluid will rise first, but the increase will gradually become slower. Subsequently, the temperature will continue to decrease. When the drilling fluid returns to a position about $1500 \mathrm{~m}$ away from the wellhead, the temperature reduction of drilling fluid is intensified. This is because when the drilling fluid just begins to return in the annulus, $\Phi_{\mathrm{in} 3}>\Phi_{\mathrm{k} 2}$ at this time, so the temperature of drilling fluid will increase. However, when the drilling fluid continues to rise, $\Phi_{\mathrm{k} 2}$ gradually increases, and $\Phi_{\text {in3 } 3}$ gradually decreases, so the 
Table 2. Input parameters for CFD.

\begin{tabular}{lclc}
\hline Parameter & Value & Parameter & Value \\
\hline Minimum annular velocity, m/s & 1.2 & Annulus width, $\mathrm{m}$ & 0.14 \\
Geothermal gradient, ${ }^{\circ} \mathrm{C} / 100 \mathrm{~m}$ & 4.3 & Formation density, $\mathrm{kg} / \mathrm{m}^{3}$ & 2.6 \\
Heat transfer coefficient $k_{2}, \mathrm{~W} /\left(\mathrm{m}^{2}{ }^{\circ} \mathrm{C}\right)$ & 430.3 & Heat transfer coefficient $k_{3}, \mathrm{~W} /\left(\mathrm{m}^{2}{ }^{\circ} \mathrm{C}\right)$ & 152.7 \\
\hline
\end{tabular}

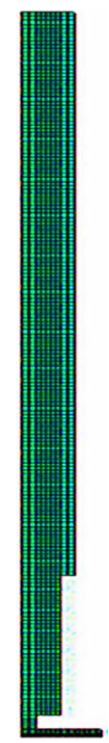

Fig. 7. The finite element model of annulus.

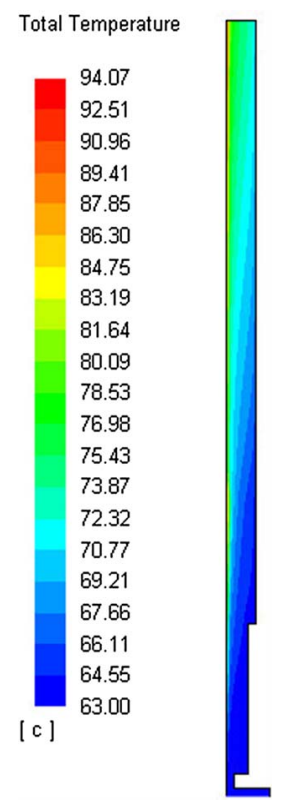

Fig. 8. CFD analysis results of 5500-6000 m.

temperature rise of drilling fluid gradually becomes slower. When $\Phi_{\mathrm{k} 2}$ is increased to be larger than $\Phi_{\mathrm{in} 3}$, the temperature of the drilling fluid in annulus begins to decrease. When the drilling fluid continues to flow upward,
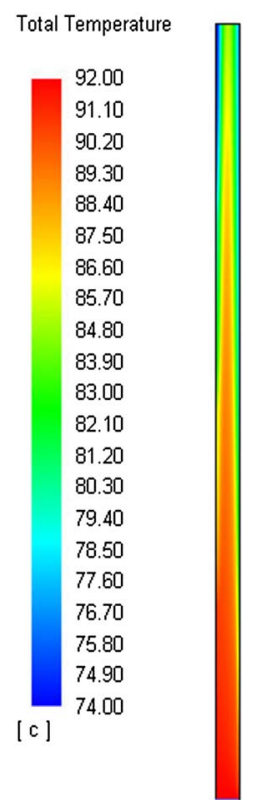

Fig. 9. CFD analysis results of 3500-4000 m

$\Phi_{\mathrm{k} 2}$ remains substantially unchanged, and $\Phi_{\mathrm{in} 3}$ decreases further, so the decrease in the temperature of the drilling fluid is further increased.

\subsection{Effect of temperature on annulus pressure}

The annulus pressure of the RMR consists of seabed pump inlet pressure, circulating liquid column pressure and cyclic pressure loss. It can be obtained as:

$$
P_{\text {ann }}=P_{\text {inlet }}+0.00981 \mathrm{ECD} h_{\mathrm{L}}+\Delta P_{\mathrm{f}},
$$

where $P_{\text {ann }}$ is the pressure of annulus, MPa; $P_{\text {inlet }}$ is the inlet pressure of subsea pump, MPa; ECD is the Equivalent Circulating Density of drilling fluid, $\mathrm{g} / \mathrm{cm}^{3} ; h_{\mathrm{L}}$ is the well depth, $\mathrm{m} ; \Delta P_{\mathrm{f}}$ is the cyclic pressure loss, MPa.

The ECD can be calculated via (Dokhani et al., 2016: Lin et al., 2016):

$$
\begin{aligned}
\operatorname{ECD}= & \frac{\rho_{\mathrm{w}} h_{\mathrm{w}}+\rho_{\mathrm{m}}\left(1-C_{\mathrm{a}}\right) h_{\mathrm{L}}}{h_{\mathrm{w}}+h_{\mathrm{L}}}+\rho_{\mathrm{s}} C_{\mathrm{a}} \\
& +\frac{\Delta P_{\mathrm{f}}}{0.00981\left(h_{\mathrm{w}}+h_{\mathrm{L}}\right)},
\end{aligned}
$$

where $\rho_{\mathrm{w}}$ is the density of seawater, $\mathrm{g} / \mathrm{cm}^{3} ; h_{\mathrm{w}}$ is the seawater depth, $\mathrm{m} ; \rho_{\mathrm{m}}$ is the static density of drilling fluid, 
Table 3. Basic data of a well in the South China Sea.

\begin{tabular}{lclc}
\hline Parameter & Value & Parameter & Value \\
\hline Formation depth, $\mathrm{m}$ & 6000 & Inner diameter of drill pipe, $\mathrm{m}$ & 0.11 \\
Seawater depth, $\mathrm{m}$ & 1600 & Outer diameter of drill pipe, $\mathrm{m}$ & 0.17 \\
Casing diameter, $\mathrm{m}$ & 0.4 & Drill size, $\mathrm{m}$ & 0.33 \\
Ocean surface temperature, ${ }^{\circ} \mathrm{C}$ & 20 & Density of seawater, $\mathrm{kg} / \mathrm{m}^{3}$ & 1020 \\
Geothermal gradient, ${ }^{\circ} \mathrm{C} / 100 \mathrm{~m}$ & 4.3 & Circulation, $\mathrm{h}$ & 7 \\
Drilling fluid density $\rho_{0}, \mathrm{~kg} / \mathrm{m}^{3}$ & 1296 & & \\
\hline
\end{tabular}

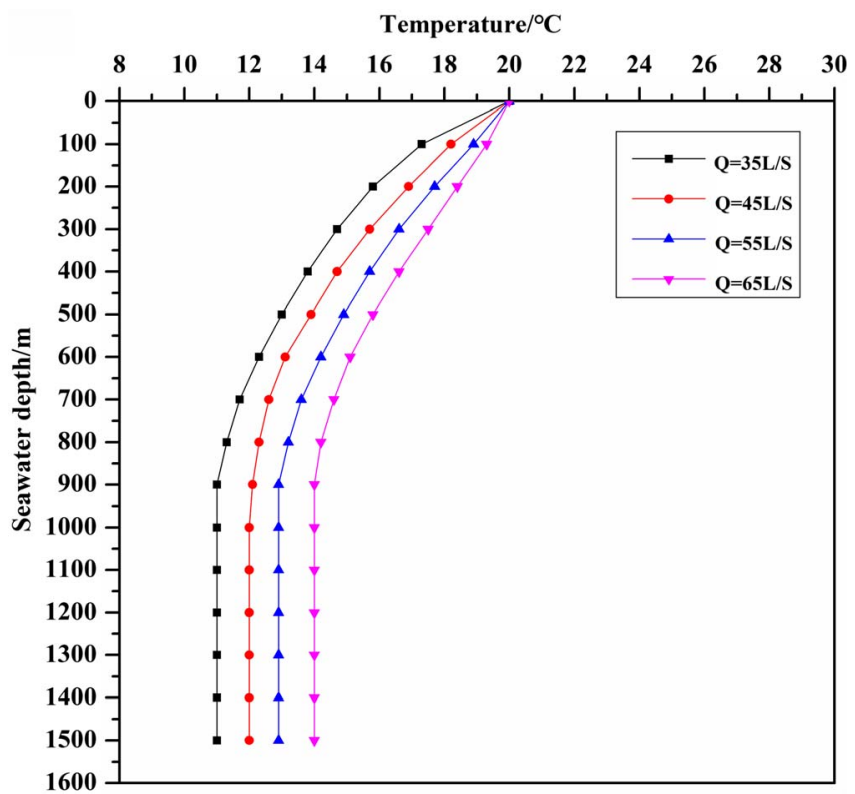

Fig. 10. Calculation results of temperature value in drill pipe in different discharge capacity.

$\mathrm{g} / \mathrm{cm}^{3} ; \rho_{\mathrm{s}}$ is the density of cuttings, $\mathrm{g} / \mathrm{cm}^{3} ; C_{\mathrm{a}}$ is cuttings concentration in annulus, dimensionless.

The static density of drilling fluid can be obtained as (Vaid and Polito, 2016):

$$
\rho_{\mathrm{m}}=\frac{\rho_{\mathrm{o}}}{1+C_{\mathrm{T}} \Delta T-C_{\mathrm{P}} \Delta P},
$$

where $\rho_{\mathrm{O}}$ is the drilling fluid density on the platform, $\mathrm{g} / \mathrm{cm}^{3} ; C_{\mathrm{T}}$ is the thermal expansion coefficient, dimensionless; $C_{\mathrm{P}}$ is the elastic compression coefficient, dimensionless; $\Delta T$ is the temperature difference between the drilling fluid at a certain depth and the platform, ${ }^{\circ} \mathrm{C}$; $\Delta P$ is the pressure difference between the drilling fluid at a certain depth and the platform, MPa.

Since the main research content of this paper is the variation law of the temperature field of the RMR, the influence of pressure change on the drilling fluid density is not considered in this section. Combined with equations (22) and (23), and the calculation results of ECD results shown in Figure 14 can be obtained.

As can be seen from Figure 14, the ECD in annulus decreases first and then increases. The main reason is that

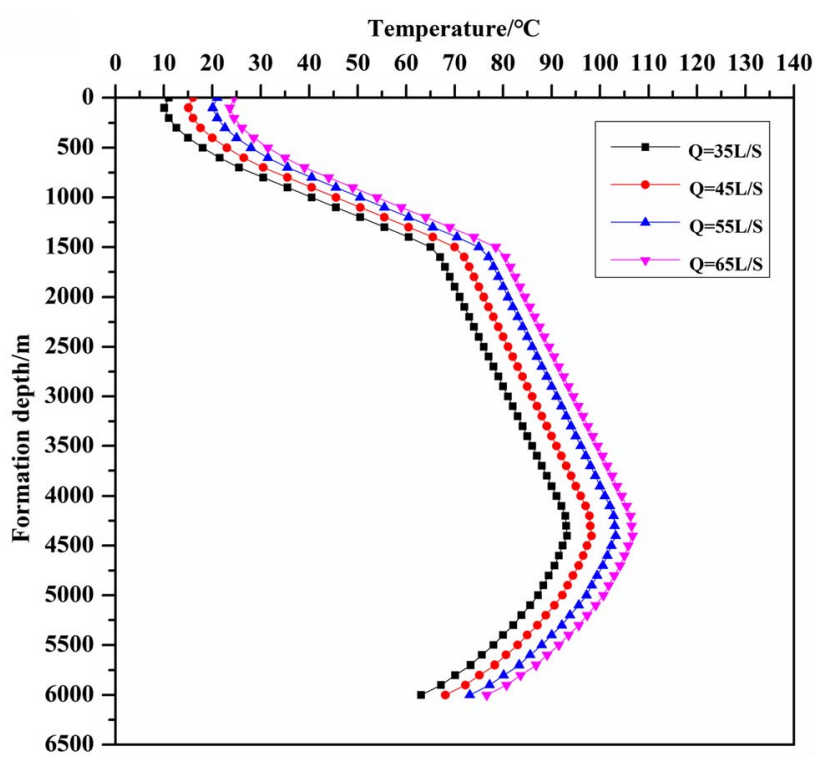

Fig. 11. Calculation results of temperature value in annulus in different discharge capacity.

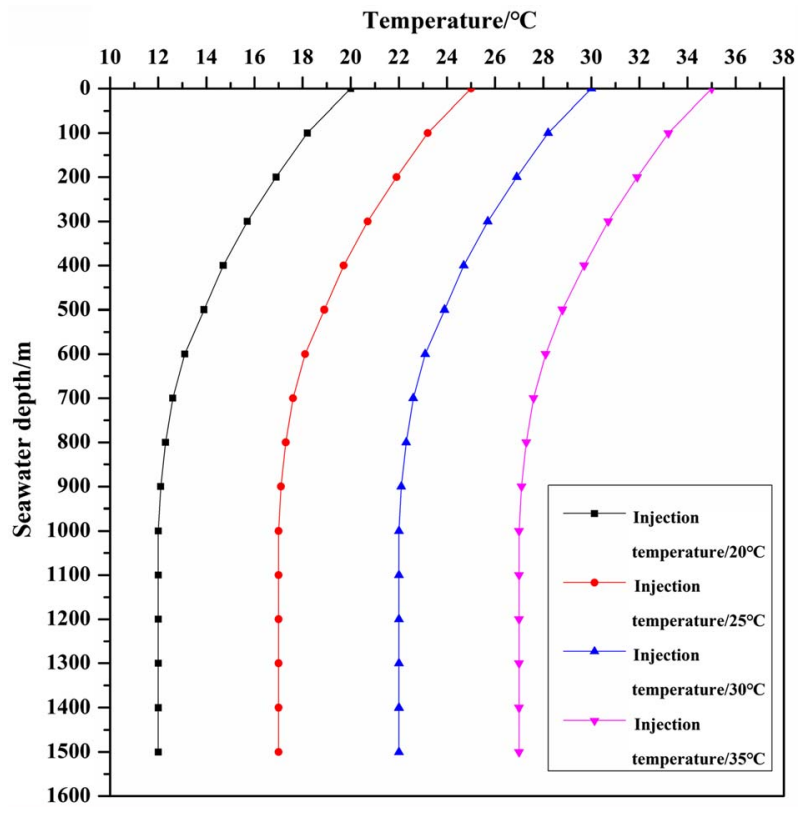

Fig. 12. Calculation results of temperature value in drill pipe in different injection temperature. 


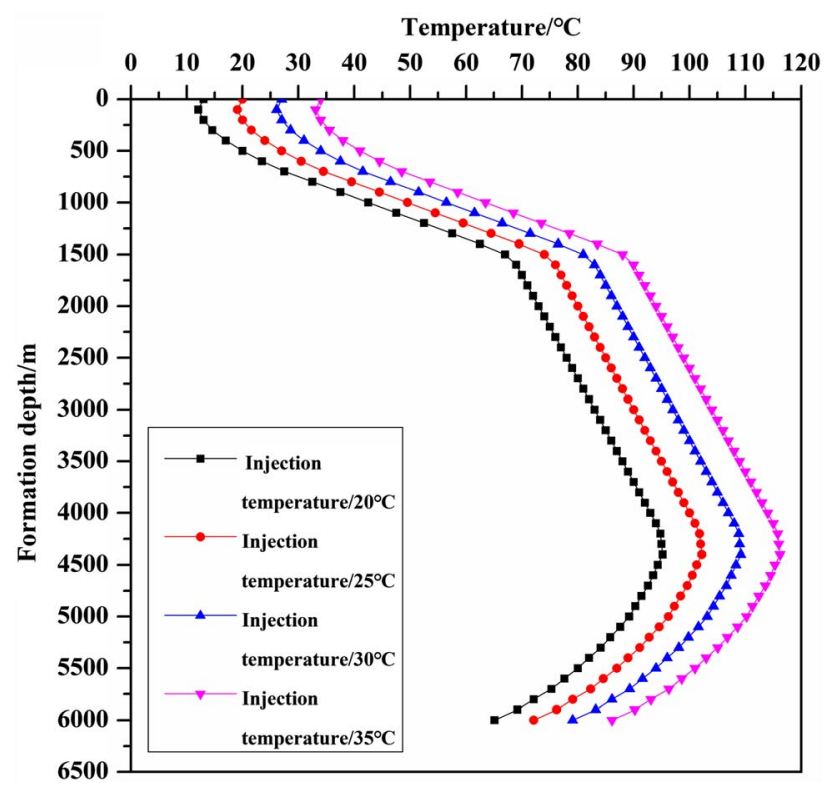

Fig. 13. Calculation results of temperature value in annulus in different injection temperature.

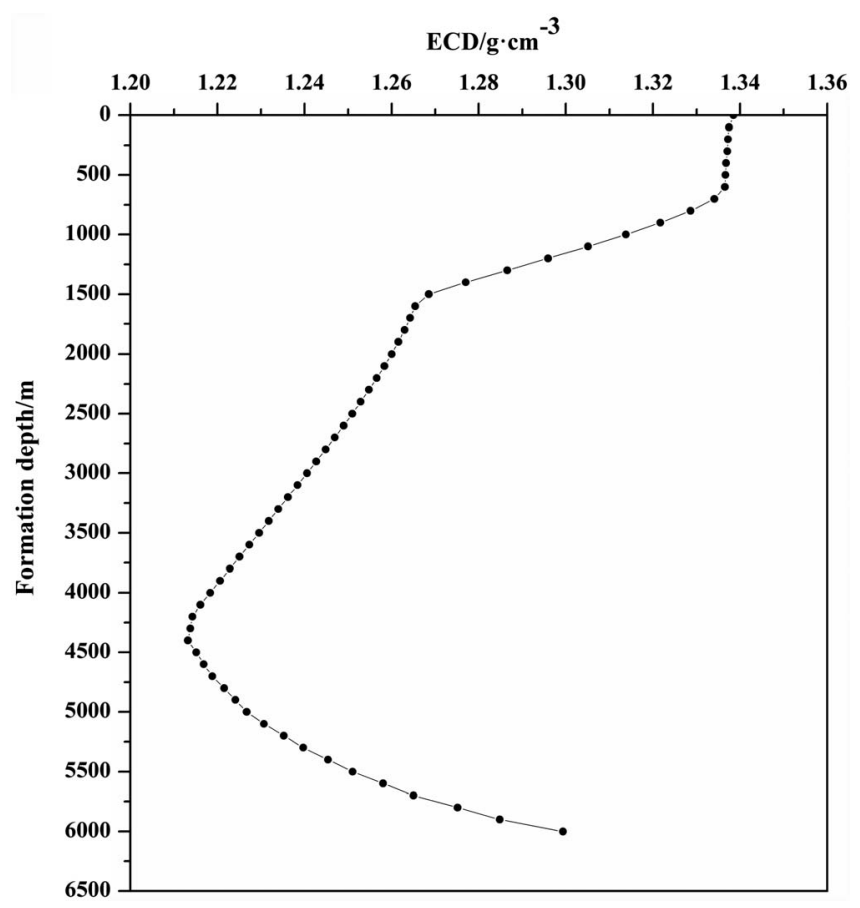

Fig. 14. Calculation results of ECD in annulus.

the temperature of drilling fluid in annulus rises first and then decreases, which causes the volume of drilling fluid to expand first and then shrink. According to $\rho=m / V$, the static density of drilling fluid first decreases and then increases. According to equation (22), the same trend of ECD in the annulus can be obtained.

Based on equation (21), the annulus pressure is calculated. The calculation results are shown in Figure 15.

It can be seen from Figure 15 that the annulus pressure is still within the safe pressure window at a well depth

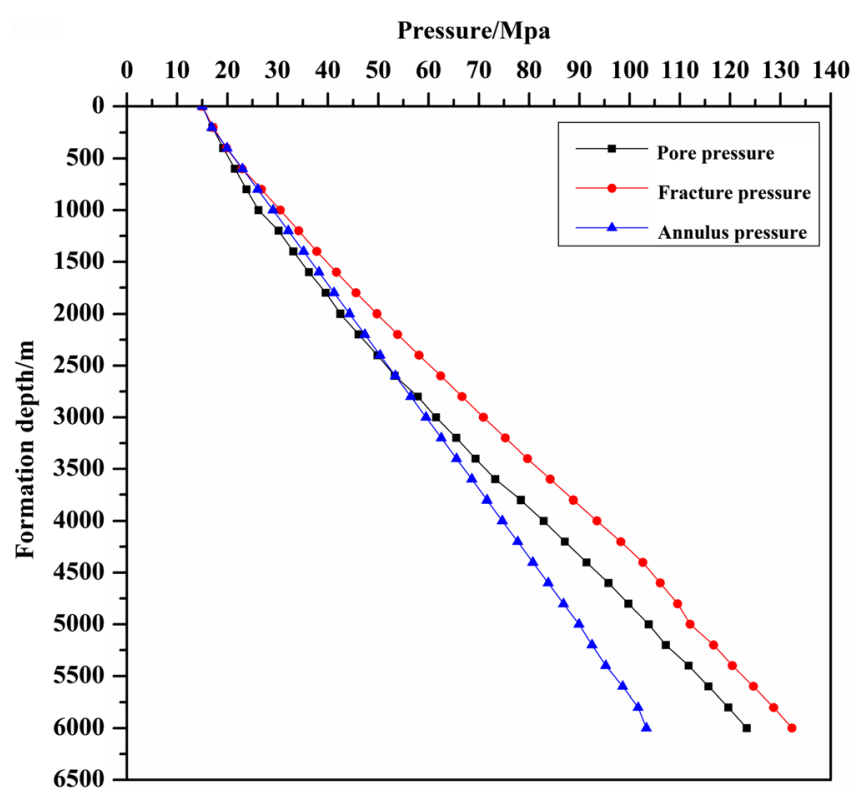

Fig. 15. Calculation results of annulus pressure.

$2500 \mathrm{~m}$. When the well depth exceeds $2500 \mathrm{~m}$, the annulus pressure is lower than the formation pressure, and the formation fluid is easy to invade the wellbore to cause the kick and blowout.

Under such conditions, the discharge capacity should be appropriately increased in combination with the actual situation to reduce the heat exchange time between the drilling fluid in the annulus and the formation, effectively suppressing the volume expansion of the drilling fluid, and making the value of ECD increases, the annulus pressure rises, allowing more well sections to be within the safe pressure window, further simplifying the casing program and reducing drilling costs.

\section{Conclusion}

1. If no insulation layer is set on the outer wall of drill pipe, the temperature of the drilling fluid in drill pipe will continue to decrease and is basically stable when the water depth is $1000 \mathrm{~m}$. This will have a great impact on the control of wellbore pressure. Therefore, in the actual drilling, it should be considered to set an insulation layer on the outer wall of drill pipe.

2. The variation of temperature of the drilling fluid in annulus is mainly affected by the two values of $\Phi_{i n 3}$ and $\Phi_{\mathrm{k} 2}$. As the two values constantly change, the temperature of the drilling fluid in annulus first increases and then decreases and the magnitude of the changing is large. Therefore, the calculation of annulus pressure needs to take into account the changing characteristics of drilling fluid temperature.

3. Under the condition of same injection temperature, the temperature of the drilling fluid at same water depth and same formation depth will increase with the increase of discharge capacity. This is very helpful 
in maintaining the temperature of drilling fluid. Therefore, it is necessary to increase the discharge capacity to a certain extent according to the actual situation when drilling.

4. With the same discharge capacity, the temperature of the drilling fluid at same water depth and same formation depth will increase with the increase of injection temperature. This also helps to keep the temperature of drilling fluid. Therefore, it is necessary to increase the injection temperature to a certain extent according to the actual situation when drilling.

5. According to the actual situation, the heat exchange between the drilling fluid in the annulus and the formation should be controlled by adjusting the discharge capacity, so as to effectively control the ECD value, so that more well sections are in the safety pressure window.

Acknowledgments. The financial support from the Natural Science Foundation of China (NSFC) (No. 51274168) and the National Key R\&D Program of China (No. 2018YFC0310202) is gratefully acknowledged.

\section{References}

Alford S.E, Asko A., Campbell M., Aston M.S., Kvalvaag E. (2005) Silicate-based fluid, mud recovery system combine to stabilize surface formations of Azeri Wells, SPE/IADC Drilling Conference, 23-25 February, Amsterdam, The Netherlands.

Beek P.J.G.V., Pereboom H.P., Slot H.J. (2016) Evaluating vibration performance of a subsea pump module by full-scale testing and numerical modeling, ASME International Conference on Ocean, pp. V005T04A059.

Chen G.M., Yin Z.M., Xu L.B., Jiang S.Q. (2007) Review of deepwater dual gradient drilling technology, Pet. Explor. Dev. 34, 2, 246-251.

Claudey E., Maubach C., Ferrari S. (2016) Deepest deployment of riserless dual gradient mud recovery system in drilling operation in the North Sea, SPE Bergen One Day Seminar, 20 April, Bergen, Norway.

Cohen J., Kleppe J., Grns T., Martin T.B. (2010) Gulf of Mexico's first application of riserless mud recovery for top-hole drilling - a case study, Offshore Technology Conference, 3-6 May, Houston, Texas, USA.

Dokhani V., Ma Y., Yu M. (2016) Determination of equivalent circulating density of drilling fluids in deepwater drilling, $J$. Nat. Gas Sci. Eng. 34, 1096-1105.

Eikemo B. (2015) Method and device for riserless drilling fluid recovery, US14356701.

Gao B., Chen G., Yin Z., Liu S.J. (2009) Deepwater riserless mud recovery drilling technology, Oil Drill. Prod. Technol. 28, 3, 381-390.
Gao D., Sun T., Zhang H., Tang H. (2013) Displacement and hydraulic calculation of the SMD system in ultra-deepwater condition, Liquid Fuels Technol. 31, 11, 1196-1205.

Hannegan D., Stave R. (2006) The time has come to develop riserless mud recovery technology's deepwater capabilities, Drill. Contractor 62, 5, 106-111.

Lin T., Wei C., Zhang Q., Sun T. (2016) Calculation of equivalent circulating density and solids concentration in the annular space when reaming the hole in deepwater drilling, Chem. Technol. Fuels Oils 52, 1, 70-75.

Michael J., Michael R. (2001) Riserless drilling technique saves time and money by reducing logistics and maximizing borehole stability, SPE Annual Technical Conference and Exhibition, 30 September-3 October, New Orleans, Louisiana.

Myers G. (2008) Ultra-deepwater riserless mud circulation with dual gradient drilling, Sci. Drill. 6, 6, 76-89.

Peyton J., Mcphee A., Eikemo B., Evans H. (2013) World first: Drilling with casing and riserless mud recovery, 6th International Petroleum Technology Conference, Beijing, China.

Scanlon T., Medeiros F. (2012) Enhanced drilling solution for tophole sections on jackup wells with environmentallyimproved method and dual-gradient drilling techniques, Offshore Technology Conference, Houston, Texas, USA.

Smith D., Tarr B., Winters W.J., Ziegler R. (2010) Deepwater riserless mud return system for dual gradient tophole drilling, SPE/IADC Managed Pressure Drilling and Underbalanced Operations Conference and Exhibition, 24-25 February, Malaysia.

Stave R., Farestveit R., Hyland S., Rochmann P.O. (2005) Demonstration and qualification of a riserless dual gradient system, Offshore Technology Conference, Houston, Texas, USA.

Stave R., Brainard R.R., Cohen J.C. (2008) Riserless mud recovery moves into deepwater, Offshore 68, 5, 100-104.

Stave R., Nordas P., Fossli B., French C. (2014) Safe and efficient tophole drilling using riserless mud recovery and managed pressure cementing, Offshore Technology Conference Asia, 25-28 March, Kuala Lumpur, Malaysia.

Thorogood J., Rolland N., Brown J., Rolland N.L. (2007) Deployment of a riserless mud-recovery system offshore Sakhalin Island, SPE/IADC Drilling Conference, 20-22 February, Amsterdam.

Vaid B.H., Polito P.S. (2016) Influence of the South China Sea biweekly sea surface temperature on the South China Sea summer monsoon especially during the Indian Ocean dipole, Atmos. Ocean 54, 1, 48-59.

Wang G. (2013) Mrl lectotype and parametric optimization for deepwater riserless drilling, China Pet. Mach. 48, 6, 97-102.

Wang Z.M., Hao X.N., Wang X.Q., Xue L., Guo X.L. (2010) Numerical simulation on deepwater drilling wellbore temperature and pressure distribution, Liquid Fuels Technol. 4828, 9, 911-919.

Ziegler R., Ashley P., Malt R.F., Stave R. (2013) Successful application of deepwater dual gradient drilling, IADC/SPE Managed Pressure Drilling and Underbalanced Operations Conference and Exhibition, 15-17 October, Moscow. 